\title{
Preparation of Epon-embedded renal tissue for scanning electron microscopy
}

\author{
WING-LING NG, L MA, KF SO \\ From the Department of Pathology, University of Hong Kong, Queen Mary Hospital, Hong Kong
}

SUMMARY A method for the preparation of Epon-embedded renal tissue for scanning electron microscopy (SEM) is described. This involves careful removal of Epon by potassium hydroxide in absolute methanol to expose the embedded kidney tissue. The method is simple and gives good surface morphology of the sectioned and trimmed surfaces of the tissue block. Both sectioned and intact glomeruli are well shown. The method also allows SEM observation of tubules and blood vessels.

Scanning electron microscopy (SEM) allows the stereoscopic examination of tissues and cells and has been applied to the study of human kidney tissues as early as $1971^{\prime}$. Since then, many workers have looked at both normal and abnormal kidneys under the $\mathrm{SEM}^{2}$ and several studies on the surface morphology of the glomerulus have been reported ${ }^{1-8}$. However, there are only a few studies on the internal morphology of the glomerulus or tubule ${ }^{578}$. This is due partly to the limited spatial resolution of the SEM and partly to difficulties in tissue preparation. Several methods were tried to visualise the glomerular internal surfaces including cryostat sectioning ${ }^{6}$, cryofracture and ultraplaning ${ }^{9}$. These methods, however, are unsatisfactory because they either produce much tissue artefact ${ }^{6}$, require elaborate preparation $^{5}$ or they fail to give true correlative SEM and transmission electron microscopic (TEM) observations. The difficulties can be avoided by using tissue originally embedded in Epon for TEM ${ }^{11}$. A method is described below in which Epon-embedded renal tissue previously sectioned and examined by TEM, are used for SEM.

\section{Material and methods}

Fourteen renal biopsy specimens were studied. These specimens were obtained by percutaneous puncture from patients suspected to have glomerular diseases. The kidney tissues were processed for diagnostic purposes for light microscopy (LM), TEM and im-

Accepted for publication 24 May 1982 munofluorescence as previously described ${ }^{\prime \prime}$. Kidney tissues for electron microscopy were fixed in $2.5 \%$ glutaraldehyde in cacodylate buffer $\mathrm{pH} 7.4$ at $4^{\circ} \mathrm{C}$ for $1 \mathrm{~h}$ and postfixed in $1 \%$ osmic acid for $2 \mathrm{~h}$. The tissues were then dehydrated through graded ethanol and propylene oxide and embedded in Epon 812. Epon blocks were processed for SEM only after routine $1 \mu \mathrm{m}$ and ultrathin sections were made for $\mathrm{LM}$ and TEM for diagnosis.

\section{REMOVAL OF EPOXY RESIN}

A superficial layer of Epon, about $0.5 \mathrm{~mm}$ in thickness, was removed from the Epon blocks to expose the embedded kidney tissue for SEM. This was done by treating the Epon blocks with an epoxy solvent. The solvent was prepared, immediately before use, by adding $5 \mathrm{ml}$ propylene oxide to $10 \mathrm{ml}$ $10 \%$ potassium hydroxide in absolute methanol. The Epon blocks were first hardened overnight in a $60^{\circ} \mathrm{C}$ oven and were then placed in glass containers, two blocks per $5 \mathrm{ml}$ epoxy solvent, which were rotated gently for 4 to $6 \mathrm{~min}$ at room temperature. The blocks were examined at two-minute intervals and the Epon removal process was stopped when about $0.5 \mathrm{~mm}$ thickness of the embedded kidney tissue had been exposed. The Epon blocks were then washed in three changes of absolute methanol and stored in absolute methanol until required.

\section{PREPARATION FOR SEM}

The treated Epon blocks were washed in one change of absolute ethanol followed by changes in graded Freon TF (Dupont, USA) in absolute ethanol to absolute Freon TF. Blocks were then air-dried at room 
temperature. The dried specimens were coated with a thin layer of gold-palladium $(30 \mathrm{~nm})$ in a Hummer II sputter coater (Technics, USA) and were examined in a Cambridge Stereoscan 150 SEM (Cambridge, $\mathrm{UK})$ at $20 \mathrm{kV}$.

\section{Results and discussion}

Adequate removal of Epon appears to be essential for successful SEM observation of Epon-embedded tissue originally intended for TEM. At least $0.5 \mathrm{~mm}$ of the renal tissue has to be exposed before good surface morphology of the block can be obtained. At low magnification by SEM, blocks with adequate removal of Epon show not only the smooth sectioned surface from which ultrathin sections were made but also the slanted trimmed surfaces (Fig. 1). Renal glomeruli, convoluted tubules and interstitium are readily identified (Fig. 1). However, if only the sectioned surface is exposed, Epon removal is likely to be incomplete and surface morphology will be obscured by residual Epon and neither glomeruli nor tubules can be recognised.

In properly prepared specimens, both sectioned and intact glomeruli are seen. Sectioned glomeruli are found mostly on the smooth sectioned surface which appears clean and devoid of artefacts. The

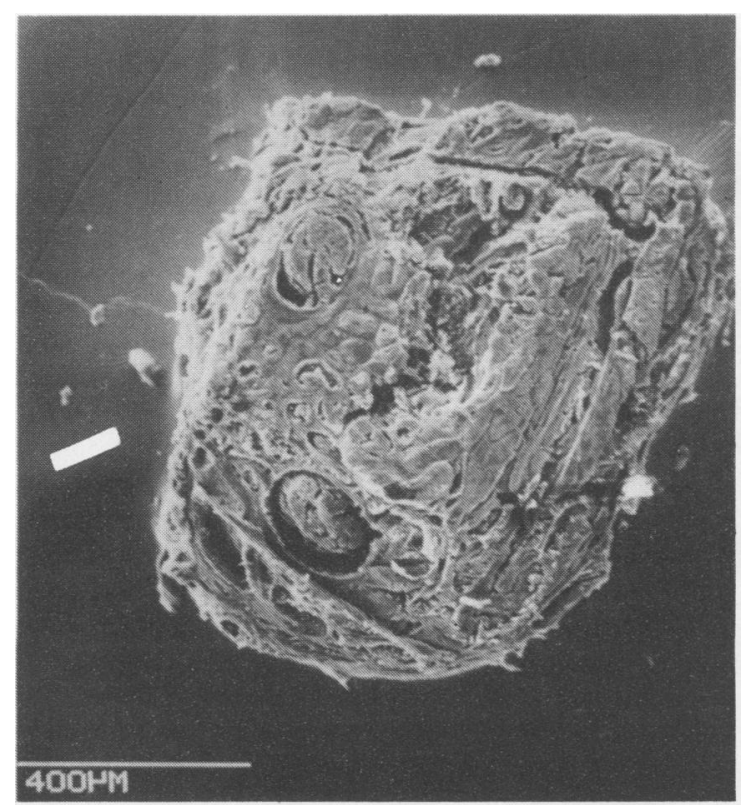

Fig. 1 Tissue block from which adequate Epon has been removed showing smooth sectioned surface and slanted trimming surfaces. Convoluted tubules and glomeruli are well shown

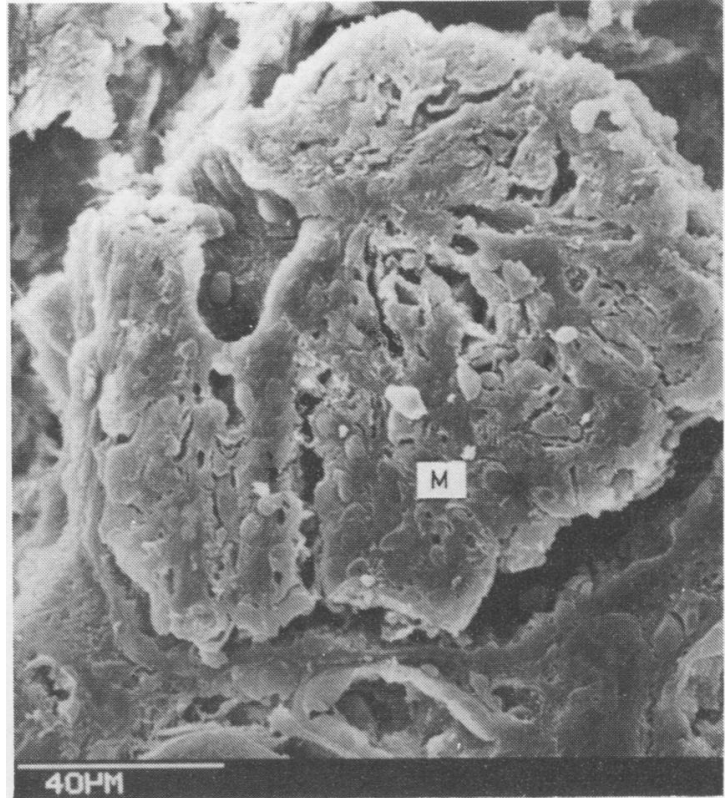

Fig. 2 Sectioned glomerulus to show mesangial proliferation $(M)$ and luminal surface of a hilar arteriole

sectioned glomeruli show intact internal architecture with recognisable epithelial cells, capillaries and mesangial areas. Glomerular abnormalities not seen by looking at surfaces of isolated glomeruli such as internal surface morphology of Bowman's capsule, glomerular vasculature and mesangial cell proliferation are revealed (Fig. 2). Intact glomeruli with removed Bowman's capsules are also seen. These appear to have clean surfaces with minimal extraneous deposits (Fig. 3) and changes of the epithelial cells and their foot processes can be readily studied (Fig. 4). Apart from glomerular surface morphology, the technique also allows SEM observation of tubules (Fig. 5) and blood vessels (Fig. 6) which are well shown.

Many other preparative methods for SEM observations of sectioned renal tissue have been described $^{5-79}$. None of them offers correlative SEM and TEM observations as demonstrated in our method. Furthermore these studies require separate sections of renal tissue and require elaborate preparation. The present technique is simple and permits retrospective correlate SEM and TEM studies of Epon-embedded tissue.

This study was supported by a grant $(335 / 046 / 9965)$ to WL Ng from the Research Grants Committee of the University of Hong Kong. 


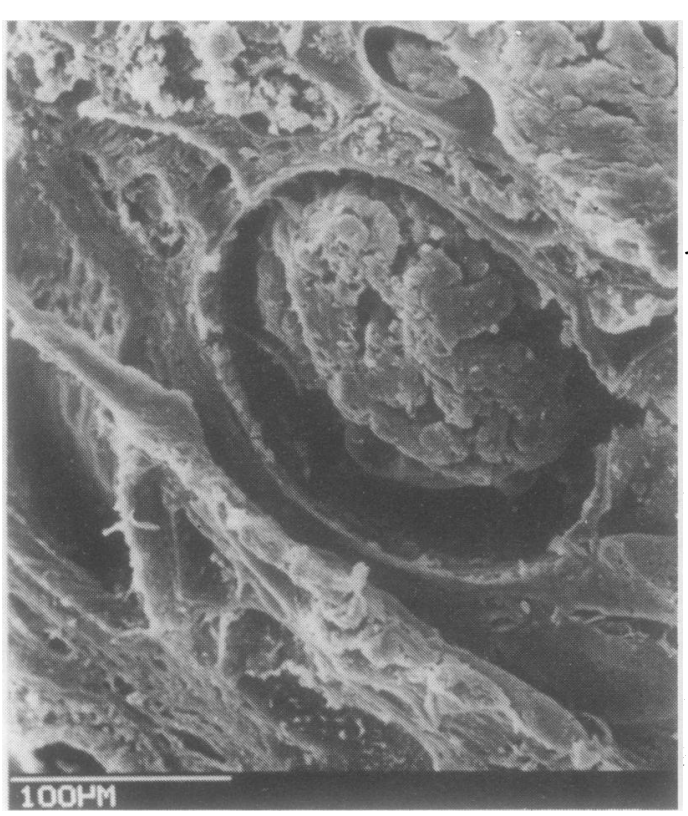

Fig. 3 Intact glomerulus from Fig. I tissue block to show well preserved external morphology

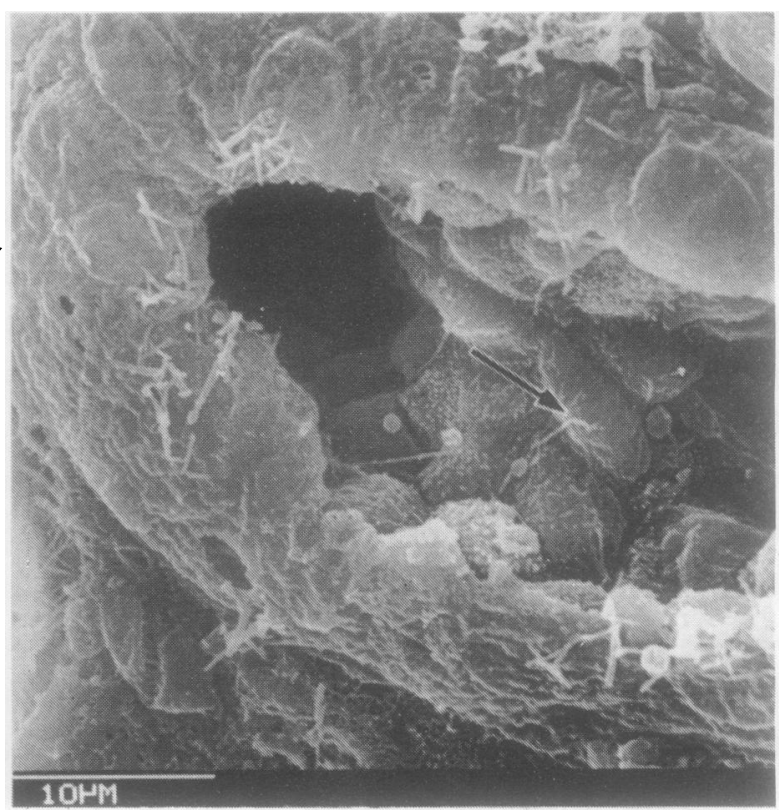

Fig. 5 Distal convoluted tubule to show cuboidal epithelial cells. Free surfaces of these cells show large numbers of short microvilli. Some exhibit a single cilium (arrow)

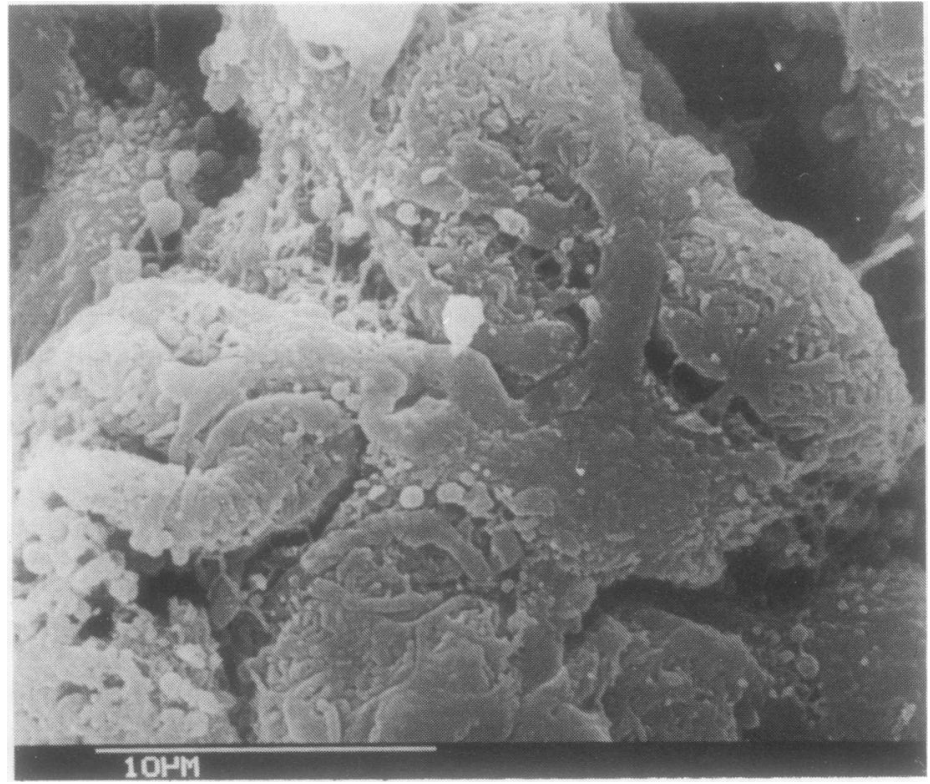

Fig. 4 Close-up view of Fig. 3 glomerulus to show epithelial cells with swollen foot processes 


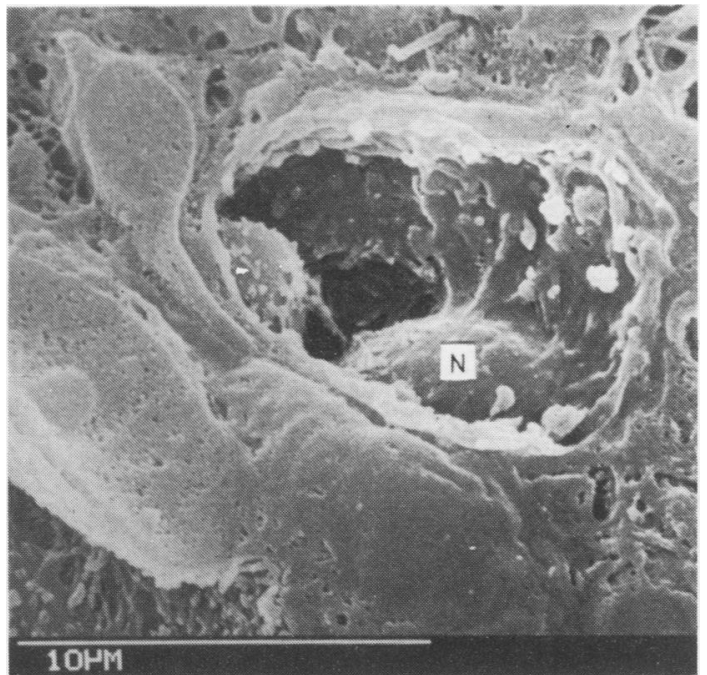

Fig. 6 Close-up view of interstitium to show a capillary with intact endothelial lining. Endothelial cell nucleus $(N)$ is seen bulging above the general surface

\section{References}

${ }^{1}$ Arakawa M. A scanning electron microscope study of the human glomerulus. Am J Pathol 1971;64:457-66.

2 Jones DB. SEM of human and experimental renal disease. In: Becker RP, Johari O, eds. Scan Electron Microsc 1979; III. AMF O'Hare: SEM Inc, 1979.
${ }^{3}$ Lehtonen E, Virtanen I, Wartiovaara J. Visualisation of human glomerular changes by scanning electron microscopy. Virchows Arch [Cell Pathol] 1973;13:259-65.

+ Arakawa M, Edanaga M, Tokunaga J. Scanning electron microscopy of the isolated human glomerulus in normal, nephritic and nephrotic situations. In: Kluthe R, Vogt A, Batsford SR, eds. Glomerulonephritis New York: John Wiley, 1977.

5 Jones DB. Correlative scanning and transmission electron microscopy of glomeruli. Lab Invest 1977;37:369-518.

- Tarpey PA, Williams G. The preparation of renal tissue for scanning electron microscopy. Med Lab Sci 1980;37:43-56.

7 Tarpey PA, Williams G. Scanning electron microscope studies of various glomerulopathies. Med Lab Sci 1980;37:57-80.

${ }^{8}$ Andrews PM. Scanning electron microscopy of human and Rhesus monkey kidneys. Lab Invest 1975;32:610-8.

${ }^{9}$ Wheeler EE, Herdson PB. Freeze fracturing and freeze drying of renal tissue for scanning electron microscopy. Am J Clin Pathol 1973;60:229-33.

${ }^{10}$ Erlandsen SL, Thomas A, Wendelschafer G. A simple technique for correlating SEM with TEM on biological tissue originally embedded in epoxy resin for TEM. In: Johari O, Corvin I, eds. Scan Electron Microsc 1973; Chicago: IIT Research Institute, 1973.

" Ng WL, Chan CW, Yeung CK, Hua SP. The pathology of primary IgA glomerulonephritis-a renal biposy study. Pathology $1981 ; 13: 137-43$

Requests for reprints to: $\mathrm{Dr} \mathrm{WL} \mathrm{Ng}$, Department of Pathology, University of Hong Kong, Queen Mary Hospital, Hong Kong. 